\title{
scripted
}

Volume 13, Issue 3, December 2016

\section{COMPUTERS AS INVENTORS - LEGAL AND POLICY IMPLICATIONS OF ARTIFICIAL INTELLIGENCE ON PATENT LAW}

\author{
Erica Fraser ${ }^{*}$
}

\begin{abstract}
The nascent but increasing interest in incorporating Artificial Intelligence (AI) into tools for the computer-generation of inventions is expected to enable innovations that would otherwise be impossible through human ingenuity alone. The potential societal benefits of accelerating the pace of innovation through AI will force a re-examination of the basic tenets of intellectual property law. The patent system must adjust to ensure it continues to appropriately protect intellectual investment while encouraging the development of computer-generated inventing systems; however, this must be balanced against the risk that the quantity and qualities of computer-generated inventions will stretch the patent system to its breaking points, both conceptually and practically. The patent system must recognise the implications of and be prepared to respond to a technological reality where leaps of human ingenuity are supplanted by $\mathrm{AI}$, and the ratio of human-to-machine contribution to inventive processes progressively shifts in favour of the machine. This article assesses the implications on patent law and policy of a spectrum of contemporary and conceptual AI inventiongeneration technologies, from the generation of textual descriptions of inventions, to human inventors employing AI-based tools in the invention process, to computers inventing autonomously without human intervention.
\end{abstract}

DOI: $10.2966 /$ scrip. 130316.305

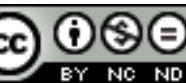

(C) Erica Fraser 2016. This work is licensed under a Creative Commons Licence. Please click on the link to read the terms and conditions.

\footnotetext{
* LLM Graduate, University of Edinburgh, United Kingdom. The author thanks Professor Burkhard
} Schafer for the discussions on this topic. 


\section{Introduction}

In light of recent extraordinary progress, we may be on the cusp of a revolution in robotics and artificial intelligence (AI) technology wherein machines will be able to do anything people can, and more. ${ }^{1}$ Recent successes have demonstrated that computers can independently learn how to perform tasks, prove mathematical theorems, and engage in artistic endeavours such as writing original poetry and music, and painting original works. ${ }^{2}$

There is a nascent but increasing interest in incorporating AI into tools for the computer-generation of inventions. Applying AI to the invention process is expected to enable innovations that would not be possible through human ingenuity alone, whether due to the complexity of the problems or human cognitive "blind spots." Further, these technologies have the potential to increase productivity and efficiency, thereby increasing the speed and decreasing the cost of innovation. ${ }^{4}$ Some even argue that computers will inevitably displace human inventors to become the creators of the majority of new innovation. ${ }^{5}$

Computer involvement in the inventive process falls on a spectrum. ${ }^{6}$ At one end, a computer could simply be used as a tool assisting a human inventor without contributing to the conception of an invention. At its most miniscule, this could consist of a spell-checker or simple calculator. Further along, a text generator may be used to fill gaps in patent documents. At the far end of the spectrum, a computer could autonomously generate outputs that would be patentable inventions if otherwise

\footnotetext{
1 "Rise of the Machines" (2015) The Economist available at http://www.economist.com/news/briefing/21650526-artificial-intelligence-scares-peopleexcessivelyso-rise-machines (accessed 29 Nov 16).

${ }^{2}$ H Devlin, "Google Develops Computer Program Capable of Learning Tasks Independently" (2015) The Guardian available at https://www.theguardian.com/technology/2015/feb/25/google-developscomputer-program-capable-of-learning-tasks-independently (accessed 29 Nov 16); S Colton, A Bundy and T Walsh, "On the Notion of Interestingness in Automated Mathematical Discovery" (2000) 53 International Journal of Human-Computer Studies 351-375; R Williams, "Google's Artificial Intelligence Writes Miserable Poetry" (2016) The Telegraph available at
} http://www.telegraph.co.uk/technology/2016/05/16/googles-artificial-intelligence-writes-miserablepoetry/ (accessed 29 Nov 16); M Brown, "World's First Computer-generated Musical to Debut in London" (2016) The Guardian available at http://www.theguardian.com/stage/2015/dec/01/beyondthe-fence-computer-generated-musical-greenham-common (accessed 29 Nov 16); N Sayej, "Vincent van Bot: the Robots Turning Their Hand to Art" (2016) The Guardian available at http://www.theguardian.com/artanddesign/2016/apr/19/robot-art-competition-e-david-cloudpainterbitpaintr (accessed 29 Nov 16).

${ }^{3}$ R King, "Rise of the Robo Scientists" (2011) 304 Scientific American 72-77, at 73; P Marks, "Eureka Machines" (2015) 227 New Scientist 32-35; R Plotkin, The Genie in the Machine: How ComputerAutomated Inventing is Revolutionizing Law \& Business (Stanford: SUP, 2009), at 67; E Knorr, "Origin of the Patents" (2001) MIT Technology Review available at https://www.technologyreview.com/s/401134/origin-of-the-patents/ (accessed 29 Nov 16).

${ }^{4}$ L Vertinsky and T Rice, "Thinking About Thinking Machines: Implications Of Machine Inventors For Patent Law” (2002) 8 Boston University Journal of Science \& Technology Law 574-613, at 576; R King et al, "The Robot Scientist Adam" (2009) 42 Computer 46-54, at 47.

${ }^{5} \mathrm{R}$ Abbott, "Hal the Inventor: Big Data and Its Use by Artificial Intelligence" in C Sugimoto, H Ekbia and M Mattioli (eds), Big Data Is Not a Monolith, (Cambridge: MIT Press, 2016) available at SSRN: http://ssrn.com/abstract $=2565950$ (accessed 29 Nov 16) at 1.

${ }^{6}$ R Abbott, "I Think, Therefore I Invent: Creative Computers And The Future Of Patent Law" (2016)

57 Boston College Law Review 1079-1126, available at http://papers.ssrn.com/sol3/papers.cfm?abstract_id=2727884 (accessed 29 Nov 16) at 19. 
created by a human. ${ }^{7}$ Some tools fall in between; for example, a computer could be used to generate several possible solutions under the guidance of humans who define the problems and select successful solutions. AI may also be incorporated into robotics, adding a physical embodiment with the potential to increase the likelihood that a computer could generate inventions without direct human intervention. ${ }^{8}$

In response to computer-generated works of art, a discussion of the implications of these works on copyright law is emerging; however, there is comparatively little examination of the repercussions of computer-generated invention on patent law. This discussion is necessary, as the adoption of these technologies have the potential to impact the patent system on a scale and of a nature that it is not currently equipped to accommodate. ${ }^{9}$ In particular, the advent of computer-generated invention will raise important questions regarding the legal implications of protecting the results of such systems, specifically, whether the right activity is being rewarded to the right person, to the right extent, and on the right conditions. ${ }^{10}$

In light of legal uncertainty in the context of rapidly advancing AI technology, this article will examine whether the current legal concepts in patent law are appropriate for computer-generated inventions, and what adaptations may be necessary to ensure that the patent system's fundamental objectives continue to be met. This discussion will explore two contemporary categories of the state of the art: automated generation of patent texts; and, AI algorithms used in the inventive process. Finally, this article will speculate on possible economic and policy impacts were AI to advance such that computers could invent autonomously "in the wild."

\section{Computer-Assisted and Computer-Generated Patent Texts}

\subsection{Technology}

Computer software can assist in or autonomously generate textual patent claims. Cloem is an example of a commercial service whereby a human operator uses a computer algorithm to create variants of existing patent claims. ${ }^{11}$ The algorithm produces a large number of permutations of a seed claim by rearranging phrases and substituting terms with alternative definitions, synonyms or antonyms. ${ }^{12}$ Cloem asserts that its algorithm is not merely random; rather, it applies patent drafting best practices to produce alternative claims that potentially enlarge the original invention's scope, or particularly in the case of substitution with antonyms, describe a distinct invention.

\footnotetext{
${ }^{7}$ Ibid, 19.

${ }^{8}$ R King et al, "The Robot Scientist Adam”, see note 4 above, at 46.

${ }^{9}$ L Vertinsky and T Rice, see note 4 above, at 576.

${ }^{10}$ D Vaver, "Sprucing Up Patent Law" (2011) 22 Intellectual Property Law Journal 63-81, at 66; B Hattenbach and J Glucoft, "Patents In An Era Of Infinite Monkeys And Artificial Intelligence" (2015) 19 Stanford Technology Law Review 32-51, at 32.

${ }^{11}$ Cloem, "Technology" available at https://www.cloem.com/flat/technology/ (accessed 29 Nov 2016); Cloem, Untitled statement on AllPriorArt (2016) available at https://www.facebook.com/cloempatent/posts/1689691667956972 (accessed 29 Nov 16). An example of Cloem-generated claims can be found at https:/www.cloem.com/flat/examples/ (accessed 29 Nov 16).

12 Ibid.
} 
These variant claims are time-stamped and optionally published online using persistent webpages. ${ }^{13}$

The art project AllPriorArt.com and its sister site AllTheClaims.com (collectively referred to hereafter as "AllPriorArt") use a technology that autonomously generates patent claims and descriptions. ${ }^{14}$ This computer system parses and randomly reassembles texts from patents and published applications from the US patent database to generate patent texts describing possible new inventions. The texts are time-stamped and published online on AllPriorArt's website. ${ }^{15}$

The vast majority of claims generated by these technologies are nonsense; however, since computer power is inexpensive and plentiful, it is possible that technologically feasible new inventions could eventually be created, akin to the infinite monkeys on infinite typewriters theorem. ${ }^{16}$ This technology is likely to become more efficient, effective and autonomous in producing useable patent texts as natural language processing improves and computing power grows even cheaper. ${ }^{17}$

\subsection{Policy Implications of Computer-Generated Prior Art}

The stated purpose of both Cloem and AllPriorArt is to generate and publish new prior art, thereby precluding the published concepts from being patented. ${ }^{18}$ In particular, the technologies assert that the generated texts will contain obvious and easily derived ideas. ${ }^{19}$ Publishing these texts will place the concepts into the public domain before they can be patented by competitors or patent trolls. ${ }^{20}$ The generation of textual patent claims could have several potential impacts on the patent system. The publication of claims so generated is aimed at serving as prior art to prevent competitors from being granted follow-on patents. ${ }^{21}$ Moreover, the original patentee could broaden their monopoly by filing these claims as new or divisional patent applications, particularly where the original specification would support them.

\footnotetext{
${ }^{13}$ Cloem, "Technology", see note 11 above.

14 Spark with Nora Young, "Fighting Patent Trolls with Stuff and Nonsense" (2016) Spark available at http://www.cbc.ca/radio/popup/audio/listen.html?autoPlay=true\&clipIds=\&mediaIds=2686963191\&co ntentarea $=$ radio\&subsection $1=$ radio1\&subsection $2=$ currentaffairs\&subsection $3=$ spark\&contenttype $=$ au $\underline{\text { dio\&title }=2016 / 04 / 17 / 1.3534351 \text {-fighting-patent-trolls-with-stuff-and-nonsense \&contentid }=1.3534351}$ (accessed 6 Dec 16).

15 AllPriorArt, “About” available at http://allpriorart.com/about/ (accessed 6 Dec 16); E Williams, "All Prior Art” (2016) available at http://hackaday.com/2016/04/21/all-prior-art/ (accessed 6 Dec 16); A Rutkin, "Computer Generates All Possible Ideas to Beat Patent Trolls" (2016) New Scientist available at https://www.newscientist.com/article/2084755-computer-generates-all-possible-ideas-to-beatpatenttrolls/ (accessed 6 Dec 16); see example descriptions at http://allpriorart.com and example claims at http://alltheclaims.com (accessed 6 Dec 16) .

16 N Collins, "Monkeys at Typewriters Close to Reproducing Shakespeare" (2011) The Telegraph available at http://www.telegraph.co.uk/technology/news/8789894/Monkeys-at-typewriters-closetoreproducing-Shakespeare.html (accessed 6 Dec 16).

17 B Hattenbach and J Glucoft, see note 10 above, at 39.

18 AllPriorArt, "About", see note 15 above.

19 K Noyes, "How Do You Stop Patent Trolls? This Algorithm Just Might Do the Trick" (2016) PCWorld available at http://www.pcworld.com/article/3060106/how-do-you-stop-patent-trollsthisalgorithm-just-might-do-the-trick.html (accessed 6 Dec 16).

20 A Rutkin, see note 15 above.

21 Cloem, available at https://www.cloem.com (accessed 6 Dec 16); Cloem, "Features" available at https://www.cloem.com/flat/features/ (accessed 6 Dec 16).
} 
Conversely, competitors or patent trolls could generate and file claims for the purpose of disrupting the originator and blocking implementations of the seed invention. ${ }^{22}$

\subsubsection{State of the Art}

The patentability of an invention (or its validity in litigation) depends both on its novelty and inventiveness as measured against the state of the art. ${ }^{23}$ Novelty is destroyed by the existence of a prior publication that discloses what the applicant claims to have invented in a clear and unmistakeable manner such that a person skilled in the art would be able to work it. ${ }^{24}$ An inventive step would be lacking where the claimed invention is obvious in light of the common general knowledge. ${ }^{25}$

Although the aim of publishing computer-generated patent texts is to create prior art that would prevent others from being granted follow-on patents, the usefulness and accessibility of art generated by such technologies is uncertain given the potentially massive volume of text that could be generated, and its publication outside of traditional scientific and industrial fora. ${ }^{26}$ This raises important questions regarding the legal significance that such material should be given. ${ }^{27}$

Patent applicants are assumed to be knowledgeable of an expansive set of prior art. ${ }^{28}$ The state of the art "comprises all matter which has at any time before the priority date of that invention been made available to the public by written or oral description, by use or in any other way." 29 Online publication on a website is recognised by the European Patent Office (EPO) and the UK courts as prior art so long as it is available without any bar of confidentiality. ${ }^{30}$ Moreover, obscurity is not a bar to a publication being considered part of the state of the art. ${ }^{31}$ The EPO Board of Appeal has held that a document stored on the Internet but only accessible via a specific URL would be considered a disclosure that had been made publically available if, before the filing or priority date of the patent or patent application, it:

i) could be found through a public web search engine by using one or more keywords related to the essence of the content of that document; and,

\footnotetext{
22 D Crouch, "Would You Like 10,000 Cloems with that Patent?" (2014) available at http://patentlyo.com/patent/2014/10/would-cloems-patent.html (accessed 6 Dec 16).

${ }^{23}$ Patents Act 1977, ss 2(1), 3.

${ }^{24}$ SmithKline Beecham Plc's (Paroxetine Methanesulfonate) Patent [2006] RPC 10; General Tire \& Rubber Company v Firestone Tyre \& Rubber Company Limited, [1972] RPC 457 at 485-486.

25 Patents Act 1977, s 3.

${ }^{26}$ Cloem, available at https://www.cloem.com/ (accessed 29 Nov 16); Cloem, "Features" available at https://www.cloem.com/flat/features/ (accessed 29 Nov 16); Spark, see note 14 above.

${ }^{27}$ B Hattenbach and J Glucoft, see note 10 above, at 41

${ }^{28}$ Ibid, 40; In re: Winslow, 365 F2d 1017, 1020 (CCPA 1965).

${ }^{29}$ Patents Act 1977, s 2(2); see also Convention on the Grant of European Patents (European Patent Convention), s 54(2): "everything made available to the public by means of a written or oral description, by use, or in any other way, before the date of filing of the European patent application."

30 European Patent Office, "Guidelines for Examination", ss 7.5, 7.5.1 available at http://www.epo.org/law-practice/legal-texts/html/guidelines/e/index.htm (accessed 29 Nov 16); Unwired Planet International Ltd v Huawei Technologies Co Ltd \& Ors [2015] EWHC 3366 (Pat).

${ }^{31} \mathrm{C}$ Waelde et al, Contemporary Intellectual Property: Law and Policy, 3rd ed (Oxford: OUP, 2014), at 11.82; Bristol-Myers Co's Application, [1969] RPC 146.
} 
ii) remained accessible at that URL for a period of time long enough for a member of the public to have direct and unambiguous access. ${ }^{32}$

Patent texts published by AllPriorArt and Cloem would likely meet this test as they can be found using the public search engine on their respective websites, are indexable by third party search engines, and are directly and unambiguously accessible to the public. ${ }^{33}$ Cloem asserts that its unpublished texts are protected by technical means and are not available to the public; therefore, these texts would likely not be considered part of the state of the art. ${ }^{34}$

Physical accessibility is not determinative, however, if the computer-generated texts would not actually be instructive to the skilled reader. The High Court of Justice of England and Wales has held that "available to the public" does not merely mean physically accessible, but also "sufficiently intellectually instructive [to] the skilled person using their common general knowledge." 35 In particular, a piece of art may not be instructive if "the matter may be contained in a document but so submerged in it as not to be available." 36 This may be a barrier to AllPriorArt and Cloem's computergenerated patent texts being considered as part of the state of the art if it could be argued that the relevant prior art is hidden within vast amounts of nonsensical text. One would need to assess the quantity and relative proportion of published useful prior art and the level of difficulty in locating it. ${ }^{37}$

Furthermore, it is unlikely that patent texts published by AllPriorArt or Cloem would be considered within the technological field of an invention. That the skilled person would not have discovered the text is irrelevant in the assessment of novelty or obviousness in light of a single reference, but it would be pertinent in assessing obviousness in light of a combination of pieces of prior art from disparate technical fields. ${ }^{38}$ In this case, a piece of art from a different field should only be considered where the problem in question would have prompted search in those fields. ${ }^{39}$ It is reasonable to expect the skilled person to be aware of the broader general field in which the same or similar problems arise, as well as closely related parallel fields. ${ }^{40}$ Currently, the webpages for AllPriorArt and Cloem are unlikely to be considered within the relevant field unless otherwise published or linked-to from a more relevant source. It is unlikely that anyone could remain abreast of computer-generated patent

\footnotetext{
${ }^{32}$ T 1553/06 (Public availability of documents on the World Wide Web/PHILIPS) of 12.3.2012 [2012] available at http://www.epo.org/law-practice/case-law-appeals/recent/t061553eu1.html (accessed 29 Nov 16).

${ }^{33}$ See Cloem, "Search" available at https://www.cloem.com/search/ (accessed 29 Nov 16); see the search fields on each of http://allpriorart.com and http://alltheclaims.com (accessed 29 Nov 16); AllPriorArt, "About", see note 15 above; Cloem, "Terms of Service" available at https://www.cloem.com/terms/latest/ (accessed 29 Nov 16).

${ }^{34}$ Cloem, "Terms of Service", see note 33 above.

${ }^{35} \mathrm{C}$ Waelde et al, see note 31 above, at 11.83; H Lundbeck A/S v Norpharma SpA, [2011] EWHC 907 (Pat).

${ }^{36}$ H Lundbeck A/S $v$ Norpharma $S p A$, see note 35 above.

${ }^{37}$ B Hattenbach and J Glucoft, see note 10 above, at 40.

${ }^{38}$ See eg Wake Forest University Health Sciences \& Ors v Smith \& Nephew Plc \& Anor [2009] EWCA Civ 848; UKIPO, Manual of Patent Practice at paras 3.73.1 available at https://www.gov.uk/guidance/manual-of-patent-practice-mopp/section-3-inventive-step (accessed 29 Nov 16).

${ }^{39}$ Dow Chemical Company (Mildner's) Patent [1973] RPC 804; UKIPO, Manual of Patent Practice, see note 38 above, at paras 3.43-3.44.

${ }^{40} \mathrm{~T}$ 176/84, [1985] OJEPO 2/86.
} 
texts published on these websites. ${ }^{41}$ If these patent text-generation technologies became better known and widely used, the argument could be made that the skilled person would know to consult them. Were this the case, any argument to exclude these texts would be less persuasive.

In light of these considerations, computer-generated patent texts could be considered part of the state of the art, which could make it more difficult to satisfy the requirements of novelty and inventive step, particularly if increasing computer power results in exponential growth in the number of such texts. ${ }^{42}$ Although most such texts will be nonsensical and the description of truly novel inventions will likely be rare, it is not impossible. ${ }^{43}$ Computer-generation of texts describing new inventions would become more likely if the right software programme constraints were used, as computing power increases, or as the algorithms for generating such texts improve. ${ }^{44}$ Publishing computer-generated patent texts could therefore preclude the patentability of legitimate inventions. Within certain fields, patents on future inventions could be pre-empted entirely; for example, antibodies can only be sequenced in finite permutations of amino acids. ${ }^{45}$ With sufficient computing power, an algorithm could potentially describe every possible antibody structure, which if published, could preclude any future patents on human inventions relating to the structure of new antibodies. $^{46}$

\subsubsection{Legal Uncertainty}

A principle aim of the patent system is to encourage research and development (R\&D) investment by providing innovators with a reasonable certainty of a return on the resulting inventions. ${ }^{47}$ If the computer generation of texts describing inventions exponentially expands the state of the art, it would put the patentability of inventions into question and increase the likelihood of issued patents being invalidated on the grounds of anticipation or lack of inventive step. ${ }^{48}$ Uncertainty regarding validity and enforceability of a patent can weaken its market value and affect a rights holder's ability to extract value through licensing or litigation. ${ }^{49}$ Further, uncertainty influences rights holders' behaviour; for example, the costs of searching and the risk of later discovering a piece of prior art that invalidates a patent could outweigh the benefits otherwise gained from patenting an invention, thereby reducing the motivation to conduct R\&D, to attempt to obtain patent protection, and to litigate. ${ }^{50}$ Beyond this

\footnotetext{
${ }^{41}$ B Hattenbach and J Glucoft, see note 10 above, at 50.

${ }^{42}$ Spark, see note 14 above.

43 Spark, see note 14 above; Noyes, see note 19 above; AllPriorArt, "About", see note 15 above; Cloem, "Terms of Service", see note 33 above.

${ }^{44}$ B Hattenbach and J Glucoft, see note 10 above, at 33; Spark, see note 14 above.

${ }^{45}$ K Elgert, "Antibody Structure And Function” in Immunology: Understanding the Immune System, at ch 4 (Hoboken: JWS, 1998).

${ }^{46}$ R Abbott, "I Think", see note 6 above, at 48.

${ }^{47}$ D Czarnitzki and A Toole, "Patent Protection, Market Uncertainty, And R\&D Investment" (2011) 93 The Review of Economics and Statistics 147-159, at 157.

${ }^{48}$ L Lemley and C Shapiro, "Probabilistic Patents" (2005) 19 Journal of Economic Perspectives 75-98, at 76 .

49 A Marco and S Vishnubhakat, "Certain Patents" (2013) 16 Yale Journal of Law and Technology 103-133, at 106.

50 J Reinganum, "The Timing of Innovation: Research, Development, and Diffusion," in R Schmalansee and R Willig (eds), Handbook of Industrial Organization (Amsterdam: Elsevier BV, 1989) 849-908, at 851; A Marco and S Vishnubhakat, see note 49 above, at 1; L Lemley and C
} 
chilling effect on R\&D and patenting, legal uncertainty within the patent system may also negate some economic benefits from other patent uses such as obtaining financing or deterring competitors from patent enforcement. ${ }^{51}$ Patents cannot unconditionally protect the applicants' investments or guarantee the validity of a patent if challenged; however, high levels of uncertainty undermine their ability to deliver the rewards that incentivise research, innovation, and knowledge diffusion the very incentives that the patent system is intended to provide. $^{52}$

\subsubsection{Patent Office Burden}

In light of the foregoing, it will fall to patent offices to search through computergenerated texts, determine whether any relevant texts form part of the state of the art, and if so, whether they preclude patentability. Considering many patent offices are already understaffed and overtaxed, and that applicants often face long backlogs in examination, the additional burden imposed by the exponential growth of the number of prior art references requiring consideration in examination may threaten the sustainability of the current level of scrutiny applied to applications. ${ }^{53} \mathrm{In}$ order to maintain the status quo or achieve higher levels of certainty, patent offices would be required to devote more resources to examination in order to conduct extensive searches of a huge amount of prior art. This degree of searching would be costly and require employing examiners who are both knowledgeable in the technical field as well as skilled in searching and interpreting computer-generated texts. Limits would need to be imposed since it would not be economically efficient to determine the validity of patents with anything approaching certainty. ${ }^{54}$ As a result, the burden may be shifted to the courts to determine ex post facto whether a particular computergenerated text forms part of the state of the art, and if so, whether that art is invalidating. ${ }^{55}$ On the other hand, this problem could have an AI solution, seeing as one of the main strengths of AI algorithms is the recognition of patterns within large amounts of data; however, such technology is nascent. ${ }^{56}$

\subsubsection{Patentability}

There is no bar to granting a patent for a computer-generated specification if it otherwise meets the statutory requirements. ${ }^{57}$ This could include filing patent

Shapiro, see note 48 above, at 84 .

${ }^{51}$ L Lemley and C Shapiro, see note 48 above, at 84.

52 A Marco, "The Value of Certainty in Intellectual Property Rights: Stock Market Reactions to Patent Litigation" (2005) Vassar College Department of Economics Working Paper No 82 at 1, available at http://economics.vassar.edu/docs/working-papers/VCEWP82.pdf (accessed 29 Nov 16); D Czarnitzki and A Toole, see note 47 above, at 147.

53 See e.g. IPKat, "EPO Performance 1 - Application Pendency Times" (2016) available at http://ipkitten.blogspot.co.uk/2016/03/epo-performance-1-application-pendency.html (accessed 29 Nov 16); R Posner, "Why There Are Too Many Patents in America" (2012) The Atlantic available at http://www.theatlantic.com/business/archive/2012/07/why-there-are-too-many-patents-inamerica/259725/ (accessed 29 Nov 16).

${ }^{54}$ L Lemley and C Shapiro, see note 48 above, at 84.

${ }^{55} \mathrm{~B}$ Hattenbach and J Glucoft, see note 10 above, at 41.

${ }^{56}$ See eg D Zhou et al, "Using Multiple Query Representations in Patent Prior-Art Search" (2014) 17 Information Retrieval 471-491.

57 Patents Act 1977, ss (1(1)(a),(b),(c); Hattenbach and J Glucoft, see note 10 above, at 43; B Hattenbach and J Glucoft, "Two New 'Startups' That Could Upend Intellectual Property Laws" (2015) 
applications for the most promising claims using the seed patent's description, or including multiple claim variants in the description of one patent application and later filing divisional applications for a subset of those claims that are determined to be commercially or legally significant. ${ }^{58}$ Alternately, computer-generated texts based on a competitor's patent could be filed in order to limit their freedom to operate. The possibility of obtaining a patent monopoly for inventions described by computer generated texts would create an incentive for those who develop and improve text generation technologies, as well as those who identify useful inventions among the potentially huge number of meaningless or nonsensical texts that are likely to be generated. ${ }^{59}$

Were a business to file patent applications using computer-generated or computerassisted claims, the best possible outcome for that business would be an enlarged monopoly around the original invention; however, the likelihood of computergenerated texts being patentable is rather low given the previously discussed likelihood for nonsensical outcomes lacking industrial application. Disregarding those, the generated text would have to describe an invention that is novel and inventively distinct from the original seed claims. Of the rare inventions described by computer-generated texts that are technically feasible, most will likely be the result of minor modifications. ${ }^{60}$ Of these, the mere substitution of synonyms is unlikely to result in an inventive step over the original patent claims, whereas the insertion of antonyms is more likely to generate something novel and inventive. ${ }^{61}$ Finally, rearranging parts of existing patent specifications is likely to lack inventiveness if there are a finite number of identified, predictable solutions, since the skilled person would have good reason to pursue the known options. ${ }^{62}$

The current technologies described above are unlikely to create patentable computergenerated texts without significant rewriting. The Patents Act 1977 requires that claims be supported by the description, which requires harmonisation between sections that is unlikely to occur randomly. Further, the specification must "disclose the invention in a manner which is clear enough and complete enough for the invention to be performed by a person skilled in the art" without undue effort. ${ }^{63}$ Where a computer-generated claim exceeds the scope of the seed patent's specification, the description will likely lack sufficiency. ${ }^{64}$ These statutory requirements are aimed at ensuring that the patent system serves its public notice function. ${ }^{65}$ From a policy perspective, the obligation to provide full and meaningful

available at http://venturebeat.com/2015/02/16/two-new-startups-that-could-upend-intellectualproperty-laws/ (accessed 29 Nov 16).

${ }^{58}$ Cloem, Untitled statement on AllPriorArt, see note 11 above.

${ }^{59}$ B Hattenbach and J Glucoft, "Two New 'Startups"”, see note 57 above.

${ }^{60}$ B Hattenbach and J Glucoft, see note 10 above, at 45.

${ }^{61}$ T Cushing, "Patent Not Sufficiently Broad Or Generic? Cloem Will Help You By Automatically Generating Dozens Of Nearly Identical Patents" (2014) available at https://www.techdirt.com/articles/20150220/08414930087/patent-not-sufficiently-broad-genericcloem-will-help-you-automatically-generating-dozens-nearly-identical-patents.shtml (accessed 29 Nov 16).

${ }^{62}$ B Hattenbach and J Glucoft, see note 10 above, at 45; see US case KSR Int'l Co v Teleflex, Inc, 550 US 398 (2007).

${ }^{63}$ B Hattenbach and J Glucoft, see note 10 above, at 50; Patents Act 1977, ss 14(3), 14(5(c); Biogen Inc $v$ Medeva Plc [1997] RPC 1, at 16.

${ }^{64}$ Biogen, see note 63; Kirin-Amgen Inc v Hoechst Marion Roussel Ltd [2004] UKHL 46.

${ }^{65} \mathrm{R}$ Plotkin, see note 3 above, at 124 
disclosure of how to perform the patented invention can be seen as the quid pro quo the patentee pays in return for the exclusive right to practice the invention. ${ }^{66}$ Therefore, if computer-generated patent specifications fail to adequately define the scope of the monopoly, it would it impede innovation as others avoid working in the area for fear of infringing the patent. ${ }^{67}$

Rather than devoting resources to re-writing computer-generated texts to meet the requirements described above prior to filing, an entity with sufficient resources to cover its filing fees could file applications containing all generated texts in hopes that some would survive examination, perhaps with amendments in response to Search or Examination Reports. This would significantly increase the burden on patent offices. In the past, overburdened patent offices have increased the likelihood that low-quality patents are granted. ${ }^{6}$ This tactic could potentially enable patent trolls by providing them with ammunition for threats, as most of their financial rewards are obtained in settlements prior to litigation. ${ }^{69}$ Ironically, this could result in the opposite effect to both AllPriorArt and Cloem's stated purposes. ${ }^{70}$

\subsubsection{Copyright Infringement}

Were a business to use a computer-assisted technology to generate patent claims or descriptions based on a competitor's specification, the question arises as to whether the competitor (or the claim generating service) can be enjoined from doing so and/or held liable on the ground of copyright infringement. Prima facie, the computerassisted or generated processes of creating patent texts described above copy a substantial part of the text from one or more upstream patent specifications. Under the Copyright Designs and Patents Act 1988 (CDPA), copyright can subsist in patent specifications, although it is not infringement to copy or issue copies of patent specifications to the public for the purposes of disseminating information. ${ }^{71}$ Copying all or a substantial part of the specification for any other purposes could infringe the copyright, however. ${ }^{72}$ It may therefore be possible to enjoin entities such as Cloem from copying patent specifications for the purpose of commercially producing computer-generated claims in the UK. This legal tactic is not available in every country, as laws regarding the subsistence of copyright in patent specifications vary internationally. For example, it may be possible in Germany where patent documents are exempted from copyright protection once published; however, the claim generation technologies described above do not currently meet the requirements that

\footnotetext{
${ }^{66} \mathrm{D}$ Vaver, see note 10 above, at 70.

${ }^{67}$ Ibid.

${ }^{68}$ B Plumer, “Innovation's Down, But Patent Trolls Are Thriving” (2011) Washington Post available at https:/www.washingtonpost.com/blogs/ezra-klein/post/innovations-down-but-at-least-patent-trolls-arethriving/2011/09/21/gIQABGdKIK blog.html (accessed 29 Nov 16).

${ }^{69}$ J Allison, M Lemley and J Walker, "Patent Quality and Settlement Among Repeat Patent Litigants" (2011) 99 Georgetown Law Journal 677-712, at 686-89; J Barta, "Patent Trolls: To Fight or to Settle, That is the Question" (2015) JIPEL Blog available at http://blog.jipel.law.nyu.edu/2015/12/patenttrolls-to-fight-or-to-settle-that-is-the-question/ (accessed 29 Nov 16).

70 Cloem, "Benefits" available at https://www.cloem.com/flat/benefits/ (accessed 29 Nov 16); AllPriorArt, "About", see note 15 above.

71 Copyright, Designs and Patents Act 1988, s 47(3); UKIPO, “Am I Allowed to Copy Patent Specifications?" available at

http://webarchive.nationalarchives.gov.uk/20140603093549/http://www.ipo.gov.uk/types/copy/c-

other/c-other-faq/c-other-faq-type/c-other-faq-type-patspec.htm (accessed 29 Nov 16).

${ }^{72}$ UKIPO, “Am I Allowed to Copy Patent Specifications?”, see note 71 above.
} 
the text of patent specifications not be modified and the original source cited. ${ }^{73}$ By contrast, in the United States copyright can subsist in patent documents subject to the limitation that "anyone may freely reproduce any patent document as it appears in the Patent and Trademark Office patent file or records." "Given the disparate national copyright protections available for patent documents contrasted with the international nature of prior art, it is unlikely that copyright enforcement would be a strong defence against the use of a patent document to generate new texts.

\section{Artificial Intelligence As a Tool in the Inventive Process}

\subsection{Technology}

Beyond textual descriptions of inventions, $\mathrm{AI}$ is being used as a tool in the invention process. ${ }^{75}$ The use of AI algorithms can be a vast improvement over traditional human invention techniques that are comparatively slow, inefficient, and often rely on happenstance. ${ }^{76}$ Computers running $\mathrm{AI}$ algorithms can be used to more rapidly and efficiently generate, simulate and evaluate large numbers of potential solutions without the usual limitations imposed by human biases or time constraints. ${ }^{77}$ This is particularly useful in complex fields where humans face difficulties manually designing inventions due to complexity, especially where there are a multiplicity of variables, as with nanotechnology and biotechnology. ${ }^{78}$ Moreover, the inventions created may be unexpected and potentially disruptive since, compared to traditional R\&D, AI can more easily draw upon multiple and possibly diverse fields. ${ }^{79}$ With the present state of AI technology, however, human ingenuity is still necessary to define targets, parameters and success criteria. ${ }^{80}$

While the use of AI has assisted in creating patentable inventions for several decades, recent improvements to AI and exponential growth in computing power will likely further enable computers to produce useful inventions and become major drivers of innovation in fields like electronics, robotics, health and pharmaceuticals, materials, and nanotechnology. ${ }^{81}$ In fact, commercial services are now available that generate

73 Urheberrechtsgesetz, ss 5(2), 39, 62(1), 63(1) (English translation available at http://germanlawarchive.iuscomp.org/?p=855 (accessed 29 Nov 16); The German Patent and Trade Mark Office (DPMA), "Questions and Answers about Patent Applications" (2016) available at http://dpma.de/english/patent/faq/index.html\#a27 (accessed 29 Nov 16).

${ }^{74}$ US Copyright Office, "Patents, Patent Applications, and Non-Patent Literature" (2014) Compendium of U.S. Copyright Office Practices $\$ 717.3$ ( $3 \mathrm{~d}$ ed) available at

http:/www.copyright.gov/comp3/chap700/ch700-literary-works.pdf (accessed 29 Nov 16); US 37 CFR $\S 1.71(\mathrm{e})(2013)$.

${ }^{75}$ R Abbott, "I Think", see note 6 above, at 4; R Plotkin, see note 3 above, at 10.

${ }^{76} \mathrm{P}$ Marks, see note 3 above.

${ }^{77}$ P Marks, see note 3 above; R Plotkin, see note 3 above, at 67; E Knorr, see note 3 above.

${ }^{78}$ G Sacha and P Varona, "Artificial Intelligence in Nanotechnology" (2013) 24 Nanotechnology 1-13, at 1 ; R Plotkin, see note 3 above, at 10.

79 P Marks, see note 3 above; Iprova, “About Us" available at http://www.iprova.com/about-us/ (accessed 29 Nov 16).

${ }^{80} \mathrm{R}$ Plotkin, see note 3 above, at 57-58, 83; E Knorr, see note 3 above.

${ }^{81}$ N Nosengo, "Can Artificial Intelligence Create the Next Wonder Material?" (2016) Nature available at http://www.nature.com/news/can-artificial-intelligence-create-the-next-wonder-material-1.19850 (accessed 29 Nov 16); R Abbott, "I Think", see note 6 above, at 4; R Plotkin, see note 3 above, at 10; The Economist, "From Not Working to Neural Networking" (2016) available 
inventions and technology optimisations using AI algorithms in place of human intelligence. ${ }^{82}$ One such company, IProva, claims that hundreds of patent applications have been filed by its customers based on the inventions it has delivered, some of which have been granted. ${ }^{83}$

The next sections will describe the state-of-the-art of AI techniques used to generate inventions.

\subsubsection{Genetic Programming}

Genetic programming ("GP”) is a form of AI modelled after the process of biological evolution that systematically solves high-level problems by improving upon a set of candidate solutions of known performance. ${ }^{84}$ The algorithm creates a new generation of solutions by applying functions corresponding to genetic operations such as crossover (akin to sexual recombination), mutation and reproduction, duplication, and deletion to the best-performing solutions from the known set. ${ }^{85}$ This process is repeated iteratively on each generation of solutions until the software converges on a set of offspring that solves the problem, or at least sufficiently meets given termination criteria. ${ }^{86}$ While human operators specify the seed solutions, fitness measures, and the termination criteria, there is usually no human intervention during the program's execution. ${ }^{87}$

At present, GP is adept at optimising pre-existing inventions but will not typically produce big inventive steps; however, GP may have a significant advantage over traditional methods of invention in fields where the interrelationships between variables are either unknown, poorly understood, or possibly wrong, or where small improvements in performance are significant. ${ }^{88}$ GP has been used to independently recreate known patented inventions, generate non-infringing work-around solutions, and is responsible for the creation of at least one known patented invention is known to have been created using GP. ${ }^{89}$ These results have caused some to argue that GP can produce "human competitive" results. ${ }^{90}$

http://www.economist.com/news/special-report/21700756-artificial-intelligence-boom-based-old-ideamodern-twist-not (accessed 29 Nov 16).

${ }^{82}$ Iprova, see note 79 above.

${ }^{83}$ Ibid.

${ }^{84}$ R Poli and J Koza, "Genetic Programming" (2014) in E Burke and G Kendall (eds), Search Methodologies: Introductory Tutorials in Optimization and Decision Support Techniques (New York: SSBM, 2014), at 143; J Koza, Genetic Programming: On the Programming of Computers by Means of Natural Selection, Vol I (Cambridge: MIT Press, 1992); R Abbott, "I Think", see note 6 above, at 10.

${ }^{85} \mathrm{R}$ Poli and $\mathrm{J}$ Koza, see note 84 above.

${ }^{86}$ Ibid.

${ }^{87}$ R Poli and J Koza, see note 84 above, at 147; E Knorr, see note 3 above.

${ }^{88}$ P Marks, see note 3 above; R Poli and J Koza, see note 84 above, at 172.

89 J Koza, "Human-Competitive Results Produced by Genetic Programming" (2010) 11 Genetic Programming and Evolvable Machines 251- 284, at 265; J Koza et al, "Evolving Inventions" (2003) Scientific American 52-59, at 52; M Keane, J Koza and M Streeter, "Apparatus for Improved GeneralPurpose PID and Non-PID Controllers” US Patent No US6847851 (B1).

90 J Koza, "Human-Competitive Results", see note 89 above, at 265; J Koza et al, "Evolving Inventions", see note 89 above, at 52. 
In the electronics field, the antenna for the miniature satellites used in NASA's Space Technology 5 mission was designed using GP algorithms. ${ }^{91}$ From a set of existing antenna designs, the designers evolved a set of novel antenna designs that met the mission's predefined requirements. The unusual structural designs produced were radically different and non-intuitive, while having a number of notable functional advantages over any known antenna. ${ }^{92}$ This application of GP demonstrated a marked improvement over conventional antenna design processes, both in the resulting design's effectiveness and the savings in time and knowledgeable labour required. ${ }^{93}$ This exemplifies that using AI to explore a wide range of possibilities without the limitations of human preconceptions can produce results with previously unachievable levels of performance. ${ }^{94}$

\subsubsection{Artificial Neural Networks}

Artificial Neural Networks (ANNs) are another form of AI that has been used as a tool to generate novel ideas. ANNs are essentially collections of binary switches that simulate neurons in a biological brain. ${ }^{95}$ These artificial neurons are organised in multiple layers to process input data with multiple levels of abstraction. With each layer, the network detects increasingly fine features of the input data and applies a "weighting" function to it. ${ }^{96}$ The weighting is set by "training" the network to recognise patterns and differences in data and to respond accordingly. ${ }^{97}$ Supervised training involves providing the network with labelled data from which to learn, whereas unsupervised training allows the network to interpret unlabelled data independently. ${ }^{98}$ Once trained, an ANN operates by feeding seed information into the input layer that applies different weights to it before passing the weighted information to a subsequent level. This weighting process is repeated at each subsequent level until the transformed data is output by the final layer. ${ }^{99}$

An example of an ANN being used as a tool to create new inventions is Dr Stephen Thaler's "Creativity Machine." 100 This system generates new inventions by disturbing the connections in one ANN to generate an output, while a second ANN perceives value in the stream of output according to the criteria set by the operator. ${ }^{101}$ The second ANN then modifies the placement and magnitudes of the disturbances in the first ANN to maximise potentially useful or meaningful outputs. ${ }^{102}$ The Creativity

\footnotetext{
${ }^{91}$ G Hornby, J Lohn and D Linden, "Computer-Automated Evolution of an X-Band Antenna for NASA’s Space Technology 5 Mission” (2006) 19 Evolutionary Computation 1-23, at 2.

92 J Lohn, G Hornby and D Linden, “An Evolved Antenna For Deployment On NASA's Space Technology 5 Mission” in U O'Reilly et al (eds), Genetic Programming Theory and Practice II (Cambridge: SSBM, 2005) 301-315, at 311.

${ }^{93}$ G Hornby et al, "Automated Antenna Design with Evolutionary Algorithms" (2006) AIAA Space 1921 , at 19.

${ }^{94}$ Ibid at 20 .

95 S Thaler, "Creativity Machine ${ }^{\circledR}$ Paradigm” in E Carayannis (ed), Encyclopedia Of Creativity, Invention, Innovation, And Entrepreneurship (Dordrecht: Springer, 2013) 447-456, at 451.

${ }^{96}$ The Economist, "From Not Working to Neural Networking" see note 81 above.

${ }^{97}$ Y LeCun, Y Bengio and G Hinton, "Deep Learning” (2015) 521 Nature 436-444, at 436.

98 Ibid, 439.

${ }^{99}$ Ibid, 437.

${ }^{100}$ A Cohen, "Stephen Thaler's Imagination Machines" (2009) 43 Futurist 28-29; S Thaler, see note 95 above, at 447.

${ }^{101} \mathrm{~S}$ Thaler, see note 95 above, at 451.

102 Ibid, 447.
} 
Machine is credited with contributing to numerous inventions; for example, from existing toothbrush designs and their performance metrics, the Creativity Machine produced a novel cross-bristled configuration for the CrossAction toothbrush design that had significant performance advantages in terms of plaque removal and gingival health compared to other toothbrush designs. ${ }^{103}$

More recently, ANNs have been used in drug discovery. ${ }^{104}$ Specifically, they have been employed for primary virtual screening of compounds in the automated design of new classes of drugs and in finding novel uses for known drugs. ${ }^{105}$ By using an ANN with many layers (a "deep neural network") to predict drug activities, AI helps to prioritise experiments and substantially reduce the necessity for experimental work. ${ }^{106}$ The benefits of employing deep neural networks are particularly acute when screening against multi-target profiles, which is otherwise extremely difficult and time-consuming, and sometimes even impossible. ${ }^{107}$ ANNs have the potential to accelerate drug discovery while improving the diversity and quality of the outcomes and reducing costs, which would improve human health and have immense value to the industry. ${ }^{108}$

\subsubsection{Robot Scientists}

The trend toward automating experimental laboratories could advance inventiongeneration technologies. ${ }^{109}$ So-called robot scientists are systems that integrate AI algorithms with physical laboratory robotics to autonomously conduct scientific experimentation. ${ }^{110}$ Robot scientists operate with minimal human intervention to supply the consumables necessary for experiments and remove the resultant waste. ${ }^{111}$

103 A Cohen, see note 100 above, at 28-29; S Thaler, see note 95 above, at 451; R Plotkin, see note 3 above, at 53, 80; M Cugini and P Warren "The Oral-B CrossAction Manual Toothbrush: A 5-Year Literature Review" (2006) 72 Journal of the Canadian Dental Association 323-323k.

104 J Ma et al, "Deep Neural Nets as a Method for Quantitative Structure-Activity Relationships" (2015) 55 Journal of Chemical Information and Modeling 263-274; T Unterthiner et al, "Deep Learning as an Opportunity in Virtual Screening" (2014) 27 Advances in Neural Information Processing Systems available at http://www.datascienceassn.org/sites/default/files/Deep $\% 20$ Learning\%20as $\% 20$ an $\% 20$ Opportunity $\% 2$ 0in\%20Virtual\%20Screening.pdf (accessed 29 Nov 16); S Kamphausen et al, "Genetic Algorithm for the Design of Molecules with Desired Properties" (2002) 16 Journal of Computer-Aided Molecular Design 551-567; G Dahl, N Jaitly and R Salakhutdinov, "Multi-task Neural Networks for QSAR Predictions" (2014) available at http://arxiv.org/abs/1406.1231 (accessed 29 Nov 16).

${ }^{105}$ R Abbott, "Hal the Inventor", see note 5 above, at 4; see also P Riley, D Webster and B Ramsundar "Large-Scale Machine Learning for Drug Discovery" (2015) available at http://research.googleblog.com/2015/03/large-scale-machine-learning-for-drug.html (accessed 29 Nov 16); J Besnard et al, "Automated Design of Ligands to Polypharmacological Profiles" (2012) 492 Nature 215-220, at 219.

$106 \mathrm{~J}$ Ma et al, see note 104 above, at 263.

${ }^{107}$ J Besnard et al, see note 105 above, at 219; J Kotz, “In Silico Drug Design” (2013) SciBX available at http://www.nature.com/scibx/journal/v6/n3/pdf/scibx.2013.50.pdf (accessed 29 Nov 16).

108 J Patel, "Science of the Science, Drug Discovery and Artificial Neural Networks" (2013) 10 Current Drug Discovery Technologies 2-7, at 7; P Riley, D Webster and B Ramsundar, see note 105 above; F Pammolli, L Magazzini and M Riccaboni, “The Productivity Crisis in Pharmaceutical R\&D” (2011) 10 Nature Reviews Drug Discovery 428-437.

${ }^{109}$ C Edwards, "From Lab Rats to Robots" (2014) 9 Engineering \& Technology 76-79, at 76.

${ }^{110}$ R King et al, "The Robot Scientist Adam", see note 4 above, at 47; R King, "Functional Genomic Hypothesis Generation and Experimentation by a Robot Scientist" (2004) 427 Nature 247-252, at 247, 251.

${ }^{111}$ R King et al, "The Robot Scientist Adam", see note 4 above, at 47. 
Existing systems have demonstrated the ability to make observations, devise hypotheses, design experiments to test its hypotheses, employ automated laboratory equipment to run those experiments, and interpret the results. ${ }^{12}$ This technology represents a marked step towards autonomous scientific discovery over the status quo where humans are primarily responsible for these functions. ${ }^{113}$ One such system, "Robot Eve", has been designed for and used in drug development, particularly, identifying compounds to fight drug-resistant malaria. ${ }^{114}$ Given a set of 5000 molecules, Robot Eve determined the characteristics of the most effective molecules, then screened only those remaining members of the set that it predicted would be most effective. Through this process, Robot Eve "discovered" a new anti-malarial use for an existing drug that was previously known only as cancer inhibitor. ${ }^{115}$

\subsection{Patentability of Computer-Assisted Inventions}

As AI becomes an integral tool in inventive processes, the commonly held understanding of inventiveness will be challenged. As mentioned above, patents have already been granted for inventions created using AI. To date, there has been no legislative or judicial consideration of the implications of patenting inventions generated in this manner. ${ }^{116}$ Given that the method of invention is not disclosed in patent prosecution, there is little reason for this to be raised as an issue. Interestingly, US law has codified a prohibition on discriminating on this basis, declaring that "(p)atentability shall not be negated by the manner in which the invention was made." 117 Although this prohibition is not codified in the UK, the results of human "search-and-test discovery" methods of invention, which are analogous with the AI algorithms described above, have to date been patentable. This should be re-examined as computer programs take a larger role in assisting inventive processes. ${ }^{118}$

\subsubsection{Novelty and Inventive Step}

The novelty of AI-generated inventions will largely depend on the inventive process used. Novelty may be absent if the algorithm used lacks variability in its outputs, or relies on similar data sets. Where an algorithm incorporates randomness or other variability, it is more likely to generate novel inventions. ${ }^{119}$ Computers also have the potential to quickly and accurately review more prior art than would be possible for a human inventor, functionality which could be incorporated into invention-generation technologies to further ensure novelty.

\footnotetext{
112 Ibid.

113 L Bunchen, "Robot Makes Scientific Discovery All by Itself" (2009) Wired available at http://www.wired.com/2009/04/robotscientist// (accessed 29 Nov 16).

${ }^{114}$ K Williams et al, "Cheaper Faster Drug Development Validated by the Repositioning of Drugs Against Neglected Tropical Diseases" (2015) 12 Journal of the Royal Society Interface available at http://rsif.royalsocietypublishing.org/content/12/104/20141289 (accessed 29 Nov 16).

115 Ibid.

${ }^{116}$ B Hattenbach and J Glucoft, see note 10 above, at 44; R Abbott, "Hal the Inventor", see note 5 above, at 12 .

11735 USC $\S 103(a)$.

${ }^{118} \mathrm{~B}$ Hattenbach and J Glucoft, see note 10 above, at 44.

${ }^{119}$ L Vertinsky and T Rice, see note 4 above, at 494.
} 
Creativity and inventiveness require more than novelty, however. ${ }^{120}$ Recall that the patentability requirement of an inventive step demands that an invention "is not obvious to the person skilled in the art, having regard to any matter which forms part of the state of the art." 121 Granting monopolies over obvious inventions would contribute little to society and prevent others from engaging in technological modifications and ordinary progresses. ${ }^{122}$ Given the ability of computers to supplant human intuition with brute force computational power, the notional skilled person and the bar for obviousness may need to be reinterpreted in light of AI in order for the inventive step requirement to serve its intended purpose. ${ }^{123}$

The first step in assessing an inventive step is identifying the notional person of ordinary skill in the art. ${ }^{124}$ This skilled person is assumed to have unlimited capacity to assimilate the vast quantities of relevant literature and to create mosaics of it, although in an uninventive manner. ${ }^{125} \mathrm{AI}$ has significantly raised the effective skill level of ordinary inventors as computers can be substituted for certain human inventive activities. ${ }^{126}$ Therefore, the standard of the person of ordinary skill should be raised to reflect the contemporary inventor and the inventive technology typically used, regardless of how a particular invention is actually made. ${ }^{127}$ Undoubtedly, if the bar for inventive step is raised as a result of AI-generated inventions, it would likely disadvantage human inventors who do not make use of AI; however, if the inventive step is to achieve its legal purpose, it must take into account all of the tools available to an inventor, not simply personal knowledge and skill. ${ }^{128}$

Assessing the existence of an inventive step concludes with determining whether "the differences between the inventive concept and the prior art constitute steps which would have been obvious to the person skilled in the art." ${ }^{129}$ What will be considered obvious, and therefore unpatentable, must reflect changing inventive practices. For example, an invention that on its surface may seem inventive, may in fact be the obvious output of a computer programmed to generate inventions "like hot water from a kettle." 130 An invention that results from a computer performing a large number of trivial calculations or brute force trial-and-error testing may seem non-obvious on its face because it had not been foreseen; however, the invention may be seen as obvious because of the inevitability of discovery as anyone having ordinary skill using one of the above-described AI algorithms could have produced the same result. ${ }^{131}$ Since this knowledge should be imputed to the skilled person, it would not amount to an ex post

\footnotetext{
${ }^{120}$ A Bundy, "What is the Difference Between True Creativity and Novelty" (1994) 17 Behavioral and Brain Sciences 533-534.

121 Patents Act 1977, s 3.

122 WIPO Standing Committee on the Law of Patents, "Study on Inventive Step" (2015) http://www.wipo.int/edocs/mdocs/scp/en/scp_22/scp_22 presentation_inventive_step.pdf (accessed 29 Nov 16).

${ }^{123}$ L Vertinsky and T Rice, see note 4 above, at 39; R Plotkin, see note 3 above at 102.

${ }^{124}$ Windsurfing International Inc v Tabur Marine (GB) Ltd [1985] RPC 59 and Pozzoli SPA v BDMO SA [2007] EWCA Civ 588.

${ }_{125}$ Technograph Printed Circuits Ltd v Mills \& Rockley (Electronics) Ltd [1972] RPC 346 at 355.

${ }^{126} \mathrm{~L}$ Vertinsky and T Rice, see note 4 above, at 602; R Plotkin, see note 3 above, at 104.

${ }^{127} \mathrm{~L}$ Vertinsky and T Rice, see note 4 above, at 595; R Plotkin, see note 3 above, at 104-05, 111.

${ }^{128} \mathrm{R}$ Plotkin, see note 3 above, at 107, 110.

${ }^{129}$ Windsurfing International, see note 124 above, at para 23.

${ }^{130} \mathrm{~L}$ Vertinsky and T Rice, see note 4 above, at 595; P Marks, see note 3 above; R Plotkin, see note 3 above, at 160 .

${ }^{131}$ L Vertinsky and T Rice, see note 4 above, at 596; R Plotkin, see note 3 above, at 108.
} 
assessment prohibited by the requirement that the inventive step be "viewed without any knowledge of the alleged invention as claimed." 132 If the knowledge of AI technologies were not taken into account in assessing obviousness, it would result in unwarranted monopolies being granted where the technologies were employed, which may impede innovation. ${ }^{133}$ The higher standard should be applied even in cases where invention-generation technology is not used; if not, applying the existing lower standard would amount to rewarding ignorance of the state of the art. ${ }^{134}$

Raising the bar for an invention to be considered non-obvious as suggested above could result in the assessment of obviousness becoming a function of the level of computational capacity required to attain the invention in question. ${ }^{135}$ For example, technological advances could have a limiting effect on the patentability of inventions arrived at through repeated trial-and-error or data mining, whether conducted by human effort or through AI. ${ }^{136}$ Moreover, this more stringent standard could have particular impact in certain fields such as drug discovery where inventions are regularly made through well-understood, routine, (or) conventional techniques like molecular screening, akin to trial-and-error testing or finding new uses for existing compositions based on known characteristics, not unlike pattern recognition in data mining. ${ }^{137}$ Additionally, accounting for AI's superior abilities to combine references between disparate fields without being limited by human tunnel-vision or biases in assessing inventiveness would result in the standard being raised substantially for the ever-increasing number of combinatorial inventions. ${ }^{138}$

\subsubsection{Patentable Subject Matter}

The AI technologies described above enable automatic transformation of functional descriptions of desired outcomes into tangible patentable inventions. ${ }^{139}$ From this starting point, an AI algorithm can produce a multiplicity of results; therefore, a functional description can represent a broad class of inventions without describing each instance of the class individually. ${ }^{140}$ Given this context, it has been suggested that in exchange for the disclosure of an abstract problem definition that can be solved through an AI algorithm, a patentee should be able to obtain a monopoly over the entire class of inventions that the algorithm would produce. ${ }^{141}$ The potential breadth of the underlying invention corresponding to an abstract description could justify a broad patent monopoly. ${ }^{142}$ Without patent protection, there is a risk of market failure as developing this new technology is complex and resource-intensive, at least

\footnotetext{
132 Windsurfing International, see note 124 above, at para 23.

${ }^{133} \mathrm{R}$ Plotkin, see note 3 above, at 102, 111.

${ }^{134}$ Ibid, 111.

${ }^{135} \mathrm{~L}$ Vertinsky and T Rice, see note 4 above, at 596.

${ }^{136}$ R Abbott, "I Think", see note 6 above, at 56; L Vertinsky and T Rice, see note 4 above, at 595; B Hattenbach and J Glucoft, see note 10 above, at 44.

137 J Sherkow, "Negativing Invention" (2011) 2011 Brigham Young University Law Review 1091-1138, at 1121-22; P Marks, see note 3 above.

${ }^{138}$ R Abbott, "I Think", see note 6 above, at 57; H Youn et al, "Invention as a Combinatorial Process: Evidence from US Patents" (2015) 12 Journal of the Royal Society Interface available at http://rsif.royalsocietypublishing.org/content/12/106/20150272 (accessed 29 Nov 16).

${ }^{139} \mathrm{R}$ Plotkin, see note 3 above, at 113, 124.

${ }^{140}$ Ibid, 116-117.

${ }^{141}$ Ibid, 108; P Kohlhepp "When the Invention is an Inventor: Revitalizing Patentable Subject Matter to Exclude Unpredictable Processes" (2008) 93 Minnesota Law Review 779-814, at 779.

${ }^{142} \mathrm{R}$ Plotkin, see note 3 above, at 130.
} 
initially, though inexpensive and easy to copy later. ${ }^{143}$ Therefore, the potential reward of a time-limited monopoly would create an incentive for further development of inventive AI technology. ${ }^{144}$

The potential to obtain a patent monopoly will also incentivise innovators to disclose abstract problem descriptions instead of guarding them as trade secrets and depriving the public of the benefits of disclosure, including stimulating further innovation, reducing duplicative efforts, and enabling effective investment in innovation. ${ }^{145}$ The problem description, while abstract, would need to be sufficiently clear and complete to define the scope of protection afforded by the patent, and demarcate the invention from the prior art. ${ }^{146}$ Further, the disclosure would need to be sufficient to enable the skilled person to make and use the inventions falling within the scope of the class described, as well as provide the public with notice of what embodiments are covered by the patent. ${ }^{147}$ In light of the advances in AI, it has been suggested that this inquiry be judged on whether an AI-enabled computer could reproduce the work. ${ }^{148}$ This would negate the patent system's public notice function, however, which is better served by necessitating that patent specifications be capable of being understood by a skilled human mind. ${ }^{149}$

This proposal is bound to be controversial, given that an abstract functional problem description is in many ways akin to a software patent, the specification of which describes how to create the subject software. ${ }^{150}$ This is not an insurmountable barrier to patentability, however, although computer programs as such are explicitly excluded from patentable subject matter under the Patents Act 1977 and the European Patent Convention, programs that produce a technical result or contribution may in themselves be patentable. ${ }^{151}$ It is beyond the scope of this article to examine the controversy over the patentability of computer programs; however, a reasonable parallel can be drawn to speculate whether an abstract problem description run by an AI algorithm could produce a patentable technical result.

\subsubsection{Patent Floods}

The development of inventive AI technologies could cause a flood of patent applications, whether for the individual results or for broader classes of inventions. ${ }^{152}$ As a result, innovation could be stifled as anyone working in the field would need to

\footnotetext{
${ }^{143}$ Ibid, 120-122.

${ }^{144}$ Ibid, 123.

${ }^{145}$ Ibid, 120-121; B Roin, "The Disclosure Function of the Patent System (or Lack Thereof)" (2005)

118 Harvard Law Review 2007-2028, at 2009.

146 Patents Act 1977, s 14(3); C Waelde et al, see note 31 above, at 400.

${ }^{147} \mathrm{R}$ Plotkin, see note 3 above, at $118,159,163$.

${ }^{148}$ L Vertinsky and T Rice, see note 4 above, at 601; R Plotkin, see note 3 above, at 159.

${ }^{149} \mathrm{R}$ Plotkin, see note 3 above, at 159.

${ }^{150}$ Ibid, 114; In re Hayes Microcomputer Prods Inc Patent Litigation, 982 F2d 1527 at 1533-1536 (Fed Cir 1992).

${ }^{151}$ Patents Act 1977, s 1(2)(c); European Patent Convention, art 52; EPO: T 1173/97 IBM/Computer Programs [2000] EPOR 219; T 935/97 IBM/Computer Programs [1999] EPOR 301; UK: Aerotel Ltd v Telco Holdings Ltd \& Ors (Rev 1), [2007] RPC 7; Symbian Ltd v Comptroller-General of Patents, [2008] EWCA Civ 1066, [2009] RPC 1; HTC Europe Co Ltd v Apple Inc (Rev 1) [2013] EWCA Civ 451.

${ }^{152}$ R Plotkin, see note 3 above, at 9, 135.
} 
obtain licenses for numerous patents. ${ }^{153}$ It also raises the spectre of patent thickets developing, where certain entities who possess the resources to obtain countless patents have the savvy to recognise this new fertile ground, thereby concentrating legal and economic power within particular fields or markets. ${ }^{154}$ Either way, potential innovators could have little freedom to operate or be faced with paying prohibitively expensive licensing fees. Moreover, as discussed earlier with respect to the filing of computer-generated patent texts, it is unlikely that already-taxed patent offices would have the resources to effectively process such a flood of applications, resulting in delays and possibly the issuance of lower-quality patents. ${ }^{155}$

\section{Autonomous Computer-Generated Invention}

Although computers are not yet capable of completely autonomous invention, it could be on the horizon as AI undergoes fast-paced innovation enabled by the increasing availability of improved computational resources (access to which may even be rented in the cloud) and advances in Big Data. ${ }^{156}$ Breakthroughs in algorithm design increase the likelihood that computers will invent autonomously within the foreseeable future; for example, unsupervised training of deep neural networks enables a computer to find links amongst huge quantities of unlabelled data without requiring a human operator to define rules. ${ }^{157}$ Moreover, there has been a significant increase in activity in the AI field, from venture capital investment into start-ups to technology giants committing significant research budgets to the topic, which may further accelerate AIbased innovation. ${ }^{158}$

We have seen so far that while existing patent law has thus far accommodated the state of the art in computer-based invention-generation tools, albeit without judicial or legislative consideration, these technologies will likely have longer term implications on the patent system as their adoption and use increases. That said, the technologies considered above serve as tools for human ingenuity. If AI technology advanced to the extent that computers would be capable of inventing "in the wild" without human intervention, it would lead to the question of whether patent law would be capable of accommodating the resulting paradigm shift. ${ }^{159}$ In particular, foreseeable issues

\footnotetext{
${ }^{153}$ Ibid, 136

${ }^{154}$ M Meurer, "Business Method Patents and Patent Floods" (2002) 8 Washington University Journal of Law \& Policy 309-339; R Plotkin, see note 3 above, at 107, 136.

${ }^{155} \mathrm{R}$ Plotkin, see note 3 above, at 9.

${ }^{156}$ Y LeCun, Y Bengio and G Hinton, see note 97 above; Nosengo, see note 81 above; K Kelly, "The Three Breakthroughs That Have Finally Unleashed AI on the World" (2014) Wired available at http://www.wired.com/2014/10/future-of-artificial-intelligence/ (accessed 29 Nov 16); The Economist, "The Return of the Machinery Question" (2016) The Economist available at http://www.economist.com/news/special-report/21700761-after-many-false-starts-artificialintelligence-has-taken-will-it-cause-mass (accessed 29 Nov 16).

157 Y LeCun, Y Bengio and G Hinton, see note 97 above, at 442; N Nilsson, The Quest for Artificial Intelligence (Cambridge: CUP, 2009), at 511.

158 The Economist, "Return of the Machinery Question", see note 156 above; The Economist, "MillionDollar Babies" (2016) The Economist available "Mille http://www.economist.com/news/business/21695908-silicon-valley-fights-talent-universities-strugglehold-their (accessed 29 Nov 16).

159 C Davies, "An Evolutionary Step in Intellectual Property Rights - Artificial Intelligence and Intellectual Property" (2011) 27 Computer Law \& Security Review 601-619, at 601; BBC, "The Law and Artificial Intelligence" (2015) BBC Unreliable Evidence available at http://www.bbc.co.uk/programmes/b04wwgz9 (accessed 29 Nov 16).
} 
include whether computers can "invent", or whether it is by definition a human activity; whether those inventions should be eligible for patent protection; who would be considered the inventor; and what changes to patent laws would be needed to accommodate these inventions. This section will address these issues and prepare the ground for the next part which will contemplate the unforeseeable future consequences of autonomous computer inventors.

\subsection{Autonomously Generated Inventions}

Traditionally, patentable inventions have been considered to be the result of human mental processes. ${ }^{160}$ However, patent law has developed to recognise human inventor(s) in a context where there has always necessarily been at least one to recognise. Where humans are not actively involved, can computers acting autonomously "invent" as we understand the concept? ${ }^{161}$ To answer this question for the purposes of patent law, we must examine the concept of invention as a legal term of art as defined in legislation, and interpreted in jurisprudence and patent office practice. ${ }^{162}$ National legislation and international agreements fail to explicitly define the term "invention." 163 Rather, patent legislation and jurisprudence set out the qualities of patentable inventions, as well as exemptions therefrom, of which neither the Patents Act 1977, the EPC, nor international agreements explicitly require that an invention be of human origin. ${ }^{164}$

Comparatively, if we imagine contexts in which autonomous invention-generating computers would be particularly useful, from deep sea or outer space exploration where humans cannot practically perceive and solve problems in situ, to do-it-yourself problem-solving by non-technical individuals (especially armed with 3-D printers), it is arguable that the solutions produced would be patentable if invented by a human. For example, consider a situation whereby an AI-enabled machine is involved in deep space exploration at such distances that the associated lag in radio communications would make human intervention in the mission impractical. If an unforeseen local effect were encountered that prevented communication using fitted technology, it could threaten the mission. Therefore, autonomous invention-generation technology could enable the machine to engineer a novel antenna and manufacture it on site with an on-board 3D printer. If the resulting invention had wider commercial use and would otherwise have been patentable had it been conceived of by humans, patent law should evolve to allow for such a case. While autonomous computational inventions

\footnotetext{
${ }^{160}$ See e.g. C Soans, "Some Absurd Presumptions in Patent Cases" (1966) 10 Patent, Trademark and Copyright Journal of Research and Education 433-450, at 438.

${ }^{161}$ R Abbott, "I Think", see note 6 above, at 42.

162 D Vaver, "Invention in Patent Law: A Review and a Modest Proposal" (2003) 11 International Journal of Law and Information Technology 286-307, at 288.

${ }^{163}$ Eg Patents Act 1977, ss 1-4; Agreement on Trade-Related Aspects of Intellectual Property Rights ("TRIPs"), s 27.1; European Patent Convention, arts 52-54, 56-57.

${ }^{164}$ C Davies, see note 159 above, at 608; D Vaver, "Invention in Patent Law", see note 162 above, at 290; Patents Act 1977; European Patent Convention; Agreement on Trade-Related Aspects of Intellectual Property Rights, 15 Apr 1994, Marrakesh Agreement Establishing the World Trade Organization, Annex 1C, 108 Stat 4809, 1869 UNTS 299, available at https://www.wto.org/english/docs_e/legal_e/04-wto_e.htm (accessed 29 Nov 16).
} 
lack human ingenuity at the stage of invention, they should be excluded from patentability only if a sound policy distinction can be made. ${ }^{165}$

Even if a human requirement had been interpreted into law, this should be reexamined in light of the unforeseeable but conceivably boundless advancement of computational capabilities. The concept of invention is dynamic, being tied to the purpose of patent laws as they have been established, changed, and perceived over time. It evolves and grows to accommodate previously unforeseen issues raised by new technologies and contexts. ${ }^{166}$ The resulting trend has been towards wider patentability. ${ }^{167}$

\subsubsection{Incentivising Autonomous Invention through Patents}

The question of whether the outputs of autonomous AI algorithms should be patentable depends on whether the patenting of these outputs falls within the purposes and justifications of the patent system itself. The central justification for the patent system is to provide an incentive for innovative activity and the public disclosure of its results. ${ }^{168}$ The question is therefore whether automated invention should be incentivised through the patent system.

Innovation can be economically challenging given the high costs of $R \& D$ and the appropriability of the resulting knowledge. ${ }^{169}$ Innovation and its associated economic growth depend on the extent to which innovators can benefit from their creative efforts. ${ }^{170}$ Patent rights are intended to be one such incentive by providing a timelimited monopoly that allows rights holders to protect their inventions and provide the opportunity to earn rents or supranormal profits higher than those they would otherwise earn as a reasonable return on their investments of time, effort and money. ${ }^{171}$ The development of inventions and their associated knowledge often involves significant risk and uncertainty, while the use of knowledge is non-rival and non-excludable. With imitation being easier than invention, this knowledge is prone to misappropriation, creating a risk of economic market failure. Without patent protection, there is a risk that less inventive activity will take place, and if it does, it is less likely to be disclosed to the public. ${ }^{172}$

\footnotetext{
${ }^{165}$ R Abbott, "I Think", see note 6 above, at 43; R Abbott, "Hal the Inventor", see note 5 above, at 18.

${ }^{166}$ D Vaver, "Invention in Patent Law", see note 162 above, at 288, 292.

167 Ibid, 302.

168 K Lybecker, "How to Promote Innovation: The Economics of Incentives" (2014) available at http://www.ipwatchdog.com/2014/07/21/promote-innovation-the-economics-of-incentives/id=50428/ (accessed 29 Nov 16).

${ }^{169}$ Ibid.

${ }^{170} \mathrm{~A} \mathrm{Hu}$ and I Png "Patent Rights and Economic Growth: Evidence from Cross-Country Panels of Manufacturing Industries" (2013) 65 Oxford Economic Papers 675-698, at 675.

171 B Hall, "Patents and Patent Policy" (2007) 23 Oxford Review of Economic Policy 568-587, at 573; $\mathrm{Hu}$ and Png, see note 170 above, at 675; R Plotkin, see note 3 above, at 98, citing P Samuelson et al, "A Manifesto Concerning the Legal Protection of Computer Programs" (1994) 94 Columbia Law Review 2308-2431, at 2365-71.

${ }^{172} \mathrm{P}$ Belleflamme, "Patents and Incentives to Innovate: Some Theoretical and Empirical Economic Evidence" (2006) 13 Ethical Perspectives 267-288, at 278; R Posner, "Do Patent and Copyright Law Restrict Competition and Creativity Excessively?" (2012) available at http://www.becker-posnerblog.com/2012/09/do-patent-and-copyright-law-restrict-competition-and-creativity-excessivelyposner.html (accessed 29 Nov 16); R Abbott, "Hal the Inventor", see note 5 above, at 15; L Ouellette,
} 
Incentives must be carefully designed to balance between the interests of rights holders and the public. If correctly calibrated, the patent system has the potential to encourage innovation and generate economic growth. ${ }^{173}$ If the monopoly is overly broad, it could unduly reward the patentee for their actual contribution to the art and prevent anyone else from innovating in the field, thereby having a chilling effect on innovation. If the grant is too narrow, the system will not have the desired potential for economic reward and not succeed in encouraging innovation.

The preliminary question is whether incentives targeting autonomous computer systems are necessary or would be effective since computers themselves do not respond directly to incentives. ${ }^{174}$ However, although the systems in question operate autonomously, humans are needed to create and maintain them. As such, it is appropriate to consider whether the inventions generated by autonomous computer systems fit within the incentive justification of the patent system.

The next issue is whether autonomous computer-generated invention is an activity that should be incentivised. On its face, widening patentability to include inventions generated autonomously by computers would provide an incentive that would accelerate innovation and generate exponentially more inventions quicker, while requiring less skill and fewer resources than would otherwise be possible. ${ }^{175}$ Moreover, the disclosure of more new and improved technologies would benefit society as a whole. Autonomous computers may sometimes even be the only means of achieving certain inventions where complexity and shear mass of data to be processed exceeds human cognitive limitations, or where skilled human intervention is not readily accessible. ${ }^{176}$ Further, if autonomous invention technology develops to become readily accessible at low cost, a pattern many computer technologies have followed previously, it has the potential to expand the class of people with the necessary skills to invent and thereby democratise invention. ${ }^{177}$

Economically, the potential for developers of autonomous invention technologies to receive a reasonable reward for their work may depend on the availability of rewards for the downstream inventions generated by those technologies. Given the potentially high cost of R\&D and limited access to super-computing power, it is conceivable that the costs to develop the platform technology will be of sufficient scale that a monopoly over the inventing machines themselves would not provide adequate return to represent a reasonable reward. If patent monopolies over the inventions produced had independent value, they could provide sufficient incentive to develop and improve such technologies, which in turn would result in further computer-generated inventions. ${ }^{178}$ If the inventions produced were known to be potentially patentable subject matter, it could be a selling feature that would increase the likelihood that the developer would receive their reasonable reward.

“Do Patents Disclose Useful Information?” (2012) 25 Harvard Journal of Law \& Technology 531-593, at 532 .

${ }^{173} \mathrm{~K}$ Lybecker, see note 168 above.

${ }^{174}$ M Perry and T Margoni "From Music Tracks to Google Maps: Who Owns Computer-generated Works?” (2010) 26 Computer Law and Security Review 621-629, at 627.

175 B Hattenbach and J Glucoft, see note 10 above, at 50; R Abbott, "Hal the Inventor", see note 5 above, at 14; R Abbott, "I Think", see note 6 above, at 32 .

${ }^{176} \mathrm{R}$ Abbott, "Hal the Inventor", see note 5 above, at 18 .

${ }^{177}$ R Plotkin, see note 3 above, at 211.

${ }^{178} \mathrm{R}$ Abbott, "Hal the Inventor", see note 5 above, at 14; R Abbott, "I Think”, see note 6 above, at 32. 
In light of the apprehension surrounding AI generally, it is to be expected that arguments against incentivising computer-generated inventions would arise. ${ }^{179}$ Firstly, there is the concern that conferring patents over computer-generated inventions would negatively impact future human innovation as supplanting human invention with autonomous algorithms could result in the atrophy of human intelligence and the obsolescence of the scientific method. ${ }^{180}$ Further, the exceptionality of human inventive talent could evaporate as the process of invention becomes more readily available to people without significant resources or specialised skills. ${ }^{181}$ This could in turn result in the elimination of high-quality $R \& D$ jobs or even whole R\&D-intensive industries. ${ }^{182}$ Further, accelerating the pace of innovation through this technology could cause too much disruption to the innovation cycle. This would manifest in a lack of value from computer-generated inventions, as consumers are confused by the high rate of change, and potentially resulting in a failure to recognise truly groundbreaking innovations. ${ }^{183}$ Moreover, the acceleration of human technological development could have environmental effects as manufacturing an increasing number of computer-generated inventions could accelerate natural resource consumption. ${ }^{184}$

Economically, it has been suggested that the development of such technology would be more technically complicated than the vast majority of patented inventions and therefore the existing patent protection for such a system will represent more incentive than would a monopoly over its subsequent creations. ${ }^{185}$ Further, some argue that the cost of the innovative effort associated with computers autonomously producing inventions would mean that the incentive provided by patent rights is not required to increase the number of inventions; therefore, a monopoly could be overkill. $^{186}$ Autonomous invention-generation systems could conceivably create thousands of inventions in a small field, more than would be possible through conventional human invention processes, potentially resulting in a concentration of patent ownership by those with access to these systems, which could stifle innovation generally by preventing anyone else from working in the field. ${ }^{187}$ Although patent

179 See e.g. J Achenbach, "The A.I. Anxiety" (2015) The Washington Post available at http://www.washingtonpost.com/sf/national/2015/12/27/aianxiety/ (accessed 29 Nov 16); P Ford, "Our Fear of Artificial Intelligence" (2015) MIT Technology Review available at https://www.technologyreview.com/s/534871/our-fear-of-artificial-intelligence/ (accessed 29 Nov 16); T Chatfield, "How Much Should We Fear the Rise of Artificial Intelligence?" (2016) The Guardian available at https://www.theguardian.com/commentisfree/2016/mar/18/artificial-intelligence-humanscomputers (accessed 29 Nov 16).

${ }^{180} \mathrm{R}$ Abbott, "Hal the Inventor", see note 5 above, at 13; R Abbott, "I Think", see note 6 above, at 34; L Floridi, The Fourth Revolution: How the Infosphere is Reshaping Human Reality (Oxford: OUP, 2014), at 129.

${ }^{181}$ L Vertinsky and T Rice, see note 4 above, at 586.

182 R Plotkin, "About AutomatingInnovation.com" available at

http://www.automatinginvention.com/about.html (accessed 29 Nov 16).

183 S Anthony, "Innovation Gone Overboard" (2008) Harvard Business Review available at https://hbr.org/2008/03/innovation-gone-overboard/ (accessed 29 Nov 16); Fast Company, "Is Too Much Industry Innovation a Bad Thing?" Fast Company available at https://www.fastcompany.com/666201/too-much-industry-innovation-bad-thing (accessed 29 Nov 16).

${ }^{184} \mathrm{P}$ Marks, see note 3 above.

185 B Hattenbach and J Glucoft, see note 10 above, at 50

${ }^{186}$ R Abbott, "Hal the Inventor", see note 5 above, at 13; R Abbott, "I Think", see note 6 above, at 34;

R Posner, "Why There Are Too Many Patents in America", see note 53 above.

${ }^{187}$ R Plotkin, see note 3 above, at 7. 
licensing may provide a solution to gain access, the transaction costs may prove to be too high where a large number of patent-holders are involved. ${ }^{188}$

Given the great potential societal benefits of accelerating the pace of innovation and generating more patented inventions, and the potential stifling consequences of market failure, making patents available for the results of autonomous inventiongenerating computers creates an incentive that fits the patent system's justification. While there are potential scientific and economic risks, they are manageable through means other than patent exclusion. Therefore, returning to the question of whether computers can invent, it is sound to interpret the legal term of art "invention" in the context of the patent system to include the products generated by computers without human intervention.

Having concluded that computers acting autonomously can generate inventions under patent law, does that mean that the computer is an inventor?

\subsubsection{Statutory Requirement to Identify an Inventor}

Universally, national patent laws and international agreements require the identity of the inventor(s) of the advances for which a patent is sought and grant the right to the inventor(s) to be mentioned in any issued patents or published patent applications. ${ }^{189}$ In some jurisdictions, inventors whose names are deliberately excluded from a patent application have legal recourse to correct this, even when they have no ownership rights to the patent. ${ }^{190}$

Several potential justifications have been suggested for this requirement. Firstly, it has been argued that the requirement reflects a desire for recognition over and above any economic benefit stemming from the patent. Given the generally held belief that human creativity should be encouraged and recognised underpins popular and political support for the patent system, without a means for recognition, the patent system would lose legitimacy in the public view. ${ }^{191}$ Secondly, identifying the inventor has been suggested as a form of quid pro quo for employer ownership of patents rights. ${ }^{192}$ Patent legislation in some jurisdictions even sets out certain benefits for employee inventors; for example, under the Patents Act 1977 inventors are eligible under certain circumstances to receive compensation from the employer who has received outstanding benefit from an invention. ${ }^{193}$ This requirement reflects value placed on the products of human minds and the individuals who produce them. However, this idealised view of the patent system as a means of recognition of individual inventors seems anachronistic given the well-established shift toward invention by teams of employees and corporate-owned patents that serve primarily as

\footnotetext{
${ }^{188} \mathrm{M}$ Heller and R Eisenberg "Can Patents Deter Innovation? The Anticommons in Biomedical Research” (1998) $280 \quad$ Science 698-701 available at http://science.sciencemag.org/content/280/5364/698.full (accessed 29 Nov 16).

${ }_{189}$ See e.g. Paris Convention for the Protection of Industrial Property of March 20, 1883, art 4ter; Patents Act 1977, ss 13(1),(2); European Patent Convention, arts 62, 80.

${ }^{190}$ US Patent Act $§ 256$; G Dutfield, "Collective Invention and Patent Law Individualism: Origins and Functions of the Inventor's Right of Attribution" (2013) 5 The WIPO Journal 25-34, at 27.

${ }^{191}$ L Vertinsky and T Rice, see note 4 above, at 585; G Dutfield, see note 190 above, at 26, 33.

192 G Dutfield, see note 190 above, at 26.

193 Patents Act 1977, ss 40-41.
} 
impersonal business assets. ${ }^{194}$ In this non-personalised context, requiring that an inventor be named seems irrational. This is true whether the invention was created through cumulative effort or by a computer acting autonomously. ${ }^{195}$ Despite this, the requirement to identify an inventor has regulatory inertia and has heretofore failed to create any problem sufficient to cause anyone to seek to abolish it. ${ }^{196}$

\subsubsection{Autonomous Computers as Inventors}

It is unclear whether a computer that autonomously generates a patentable invention can legally be listed as an inventor. ${ }^{197}$ The issue of inventorship can be significant under current law; for example, incorrect attribution of inventorship, and therefore entitlement to a patent, can be the basis of a defence of invalidity in an infringement action. ${ }^{198}$

An inventor is a person who contributed to the formulation of the inventive concept or concepts of a patent or application. ${ }^{199}$ The prevalent view is that a new patentable concept is a "mental creation by a human being." 200 Although not expressly stated in patent statutes, jurisprudence and patent office guidelines have interpreted "inventors" as being limited to natural persons. ${ }^{201}$ If computers supplant humans in creating inventions, the proper identification of inventors would have to be considered.

The legal issue of the inventor's identity for an autonomously computer-generated invention has not been considered to date as state of the art of invention-generation technologies, such as those discussed earlier, require human operators who contribute to the inventive activity. ${ }^{202}$ From the known examples of computer-assisted inventions, their human operators have been named as the inventors; however, this would become less justifiable the more a computer contributes to the conception of the inventive concept. ${ }^{203}$ In fact, as invention-generation technology becomes completely autonomous, the difficulties of identifying an inventor will be compounded, in which case three possible outcomes remain: find a peripheral human inventor; allow the computer to be identified in the capacity of a legal person; or, eliminate the identification requirement altogether.

Identifying a human inventor for an invention autonomously generated by a computer is not straightforward. The AI algorithm designer is one possibility, as some argue that the distinction between the outputs of an algorithm and the algorithm itself is irrelevant for the purposes of IP law. ${ }^{204}$ This would parallel copyright law in the UK

\footnotetext{
${ }^{194}$ G Dutfield, see note 190 above, at 25-26; S O’Connor, "Hired to Invent vs. Work Made For Hire: Resolving the Inconsistency Among Rights of Corporate Personhood, Authorship, and Inventorship" (2012) 35 Seattle University Law Review 1227-1246, at 1242.

${ }^{195} \mathrm{G}$ Dutfield, see note 190 above, at 33.

196 Ibid, 33.

${ }^{197}$ R Abbott, "I Think", see note 6 above, at 23-24.

${ }^{198} \mathrm{G}$ Dutfield, see note 190 above, at 610.

199 University of Southampton's Applications [2005] RPC 11 at para 220.

${ }^{200}$ See e.g. C Soans, see note 160 above, at 438.

${ }^{201}$ S O'Connor, see note 194 above, at 1238; C Soans, see note 160 above, at 438.

${ }^{202}$ R Abbott, "I Think", see note 6 above, at 24.

${ }^{203}$ S Thaler, "Device for the Autonomous Generation of Useful Information" US Patent No 5,659,666; file wrapper cited in R Abbott, "I Think", see note 6 above, at 10; M Keane, J Koza and M Streeter, see note 89 above; file wrapper cited in R Abbott, "I Think", see note 6 above, at 13.

204 See parallel argument regarding copyright: J Grimmelmann, "There's No Such Thing As A Computer-Authored Work" (2016) 39 Columbia Journal of Law \& the Arts 403-416, at 408.
} 
where computer-generated works are recognised with the author "taken to be the person by whom the arrangements necessary for the creation of the work are undertaken." $^{205}$ Further, this approach would recognise those who develop autonomous invention-generation technology; however, this would not accurately reflect actual contribution to the inventive concepts of the downstream inventions. ${ }^{206}$ Another possibility could be to identify the first person to mentally recognise and evaluate the significance of a computer's results. ${ }^{207}$ This would mean that computergenerated inventions are patentable only if subsequently discovered by a person. ${ }^{208}$ Unless this recognition requires skill and knowledge, the identity of the resulting inventor may be rather arbitrary. Of both options, neither is a good fit in terms of the patent system's incentive function, as it would arguably be unfair to reward persons who made no actual conceptual contribution to creating the resulting inventions themselves. $^{209}$

Instead, the patent system could recognise the computer as the inventor of the inventions it generates. The computer would contribute and communicate all of the elements of the inventive concept, which under UK jurisprudence is sufficient to be considered as inventor of the claim. ${ }^{210}$ Legally, this would require not only accepting inventorship beyond natural persons, but also recognising computers as legal persons. The former would also allow corporate inventors, but this is arguably overdue as modern inventions are rarely the product of individual inventors, as discussed previously. ${ }^{211}$ The latter would represent a radical reappraisal of human concepts of self and society's relationship with technology; however, precedents exist where an inanimate object has been granted legal personality (albeit in a vastly different case of a dispute over the ownership of a religious idol). ${ }^{212}$ Moreover, AI algorithms can exhibit attributes of personhood, such as acting with intentionality. ${ }^{213}$ Recognising computers as legal persons would have consequences beyond inventorship, but these are arguably not insurmountable; for example, mechanisms for managing the responsibilities associated with personhood, such as civil liability, have been contemplated. ${ }^{214}$ Allowing computer inventorship will allow for credit to be given to the inventing system, thereby enabling businesses to use the number of patents issued as a selling point for such systems, and therefore promoting the progress and commercialisation of autonomous inventing technologies. ${ }^{215}$

\footnotetext{
205 Copyright, Designs and Patents Act 1988, s 9(3); See eg Nova Productions Ltd v Mazooma Games Ltd \& Ors Rev 1 [2006] EWHC 24 (Ch) at 104.

${ }^{206}$ B Hattenbach and J Glucoft, see note 10 above, at 50.

${ }^{207}$ Ex parte Smernoff, 215 USPQ 545 at 547 (Bd App 1982); R Abbott, "Hal the Inventor", see note 5 above, at 2, 13.

${ }^{208}$ R Abbott, "Hal the Inventor", see note 5 above, at 13.

${ }^{209} \mathrm{C}$ Davies, see note 159 above, at 215; R Abbott, "Hal the Inventor", see note 5 above, at 14.

210 Stanelco Fibre Optics Ltd's Applications [2005] RPC 15.

${ }^{211}$ D Burk, "Intellectual Property and the Firm" (2004) 71 University of Chicago Law Review 3-20.

${ }^{212}$ C Davies, see note 159 above, at 617; Pramatha Nath Mullick v Pradyumna Kumar Mullick, AIR 1925 PC 139.

213 D Calverley, "Imagining a Non-Biological Machine as a Legal Person" (2008) 22 AI \& SOCIETY 523-537, at 535 .

${ }^{214}$ C Davies, see note 159 above, at 618; "EU Laws Should Recognise Liability of Robots, Says MEP" Out-Law available at http://www.out-law.com/en/articles/2016/july/eu-laws-should-recognise-liabilityof-robots-says-mep/ (accessed 29 Nov 16).

${ }^{215}$ R Abbott, "Hal the Inventor", see note 5 above, at 19, 58.
} 
The final option is to eliminate the statutory requirement to identify an inventor altogether. This option would be the simplest in the cases where there is no individual human inventor who can reasonably lay claim to an invention, such as where the invention is the result of a large team effort, or of a computer whose process of invention is not purposeful or directed and is without human oversight or control. ${ }^{216}$ However, eliminating this requirement would obviate certain justifications for the patent system, such as the fair reward and moral benefit of recognition. This could have tangible impacts on scientists and engineers who gain professional credibility and even monetary benefits based on their status as a named inventor on patents. Further, since the requirement is based to a large degree on a natural understanding of fairness, eliminating it could undermine public support for the system as a whole. ${ }^{217}$ In the current context and with the prospect of autonomous computer-generated inventions, the optimal balance between perceptions of morality and fairness and the impersonal realities of inventorship is likely to maintain the option of identifying one or more human inventors only where such a person can be reasonably identified. ${ }^{218}$ This would maintain the social and financial benefits of attribution where it is warranted, while permitting the patenting of computational inventions without making radical legal changes. ${ }^{219}$

\subsubsection{Ownership}

Patent ownership is tied to inventorship, at least initially. Under the Patents Act 1977, the inventor is the first owner of a patent, unless another entity has a superior right, such as through employment or contract. ${ }^{220}$ Having concluded above that the requirement that a natural person be identified as the inventor should be eliminated, first ownership must therefore be considered. In the particular case of inventions generated by computers without human interventions, if the computer is recognised as a legal person and the inventor, the computer could be designated as the first owner. ${ }^{221}$ By granting these rights to the computer, the parties would determine their respective entitlements and give them effect through contract. ${ }^{222}$ This would require assigning or licensing all downstream inventions, which would be economically inefficient. On the other hand, it would support the creation of incentives for the development and commercialisation of autonomous invention-generation technologies in the patent system. ${ }^{223}$ A less radical solution would be to presume that the computer's owner is the first owner of any patents generated, as this would best enable various possible business models based on autonomous invention technology. ${ }^{224}$ Although economically this ownership model would likely still require a number of assignments or licenses, it would be fewer than if the computer itself were the first owner of the patents it generates. At least in this case, the computerowning company that commercialises the inventions at issue would not need

\footnotetext{
${ }^{216}$ L Vertinsky and T Rice, see note 4 above, at 586.

${ }^{217} \mathrm{G}$ Dutfield, see note 190 above, at 33.

218 Ibid, 33.

219 Patents Act 1977, ss 40-41.

${ }^{220}$ Patents Act 1977, s 7(2).

${ }^{221} \mathrm{C}$ Davies, see note 159 above, at 617.

222 Ibid, 618.

${ }^{223}$ Ibid, 617.

${ }^{224}$ Ibid, 618; see also L Vertinsky and T Rice, see note 4 above, at 609.
} 
assignments or licenses. Further, the company would have legal standing in the case of infringement actions.

\subsection{Calibrating Patent Laws}

While this article has discussed the legal implications and need for change to address current and possible future invention-generation technologies, other issues are likely to arise that will necessitate further amendments to patent law and policy as these technologies continue to advance. On the other hand, given the potential advantages of computer-generated invention processes, the effect of patent law in limiting technological development must also be considered. ${ }^{225}$

By way of example, a dramatic change in the technical landscape could result in the value of patents as an incentive for innovation being outweighed by the costs of hampering competition. ${ }^{226}$ Therefore, if computers could autonomously generate a large number of inventions at a relatively low cost, the patent scope may need to be reduced in order to rebalance the changing incentives and costs of invention. ${ }^{227}$ If too strong a protection is provided to rights holders, the results could include increasing market prices above efficient levels; encouraging the filing of defensive patenting which can contribute to the development of patent thickets; and, potentially enabling patent trolls. ${ }^{228}$ If this were the result of patenting computer-generated inventions, the patent system's 20-year monopoly may prove too great a reward for an activity that has become too easy to justify it. Reducing the patent term may sufficiently recalibrate the labour-reward balance. Alternately, instead of reducing the scope of reward, the bar for patentability could be raised to reduce the number and increase the quality of patents. For example, requiring a higher degree of industrial application could reduce the number of patents having little practical use, thereby reserving patent protection for inventions that truly benefit society. ${ }^{229}$ On the other hand, ensuring that any higher threshold is met would likely require more human screening of automated invention processes, thereby potentially negating the benefits of the autonomous nature of $\mathrm{AI}{ }^{230}$

A significant challenge to adjusting patent law and policy will be the inherent difficulties in empirically measuring patent effectiveness, particularly across jurisdictions and within nascent technological fields like computer-generated invention. ${ }^{231}$ Even within patent offices, which may be well placed to provide insight into the effects of technological change on patenting behaviour, there is no reliable way of knowing how inventions are made and patent offices have scant surplus administrative resources to investigate. ${ }^{232}$ Therefore, a preliminary step for

\footnotetext{
${ }^{225}$ BBC, "The Law and Artificial Intelligence", see note 159 above.

${ }^{226}$ R Abbott, "Hal the Inventor", see note 5 above, at 15.

${ }^{227} \mathrm{~L}$ Vertinsky and T Rice, see note 4 above, at 613.

${ }^{228}$ R Posner, "Do Patent and Copyright Law", see note 172 above.

${ }^{229}$ L Vertinsky and T Rice, see note 4 above, at 608.

${ }^{230}$ Ibid, 609.

${ }^{231}$ R Abbott, "Hal the Inventor", see note 5 above, at 15

232 J Sherkow, "And How: Mayo v. Prometheus and the Method of Invention" (2013) 122 Yale Law Journal Online 351-358 available at http://www.yalelawjournal.org/pdf/1144_obtqyfxe.pdf (accessed 29 Nov 16), at 356.
} 
accumulating useful data would be to require the disclosure of the "method of invention." 233

Computer generated invention technologies will radically change the inventive process, and may yield vast and unpredictable impacts on the patent system. Accordingly, a continuous re-examination of whether the patent system's supporting rationale remains appropriate will be required as AI technology progresses. ${ }^{234}$

\section{Conclusion}

The patent system must recognise the implications of and be prepared to respond to a technological reality where leaps of human ingenuity are supplanted by AI, and the ratio of human-to-machine contribution to inventive processes progressively shifts in favour of the machine. ${ }^{235}$ Given the great potential societal benefits of accelerating the pace of innovation, the system must adjust to ensure it continues to appropriately protect intellectual investment and incentivise the development of computer-generated inventing systems; however, this must be balanced against the risk that the quantity and nature of computer-generated inventions will stretch the patent system to its breaking points, both conceptually and practically. The balance will be increasingly challenging if, as some believe, technology will advance such that computers and AI will displace humans from the inventive process altogether, even if not in the immediate future. ${ }^{236}$ Policy makers should continuously examine these developments and their potential effects to ensure that the fundamental rationale and justifications for the patent system are being fulfilled. If these issues are not addressed in a proactive manner, it will fall to patent practitioners, patent examiners, and the courts to adapt patent law and practice based on the facts of individual cases without necessarily considering the broader policy implications of the precedents set. ${ }^{237}$ Notwithstanding, the advent of truly autonomous AI portends exciting times for technologists and patent practitioners alike. Radical though they may be, the changes that AI will bring shall, if properly managed, reinforce the societal benefits that the patent system was always meant to deliver.

\footnotetext{
${ }^{233}$ C Wamsley, "Flashes of Genius, Toiled Experimentation, and Now Artificial Creation: A Case for Inventive Process Disclosures" (2011) LLM dissertation, The George Washington University, available at http://etd.gelman.gwu.edu/etd_11165/11165.pdf (accessed 29 Nov 16).

${ }^{234} \mathrm{~L}$ Vertinsky and T Rice, see note 4 above, at 613; R Plotkin, see note 3 above, at 146.

${ }^{235} \mathrm{P}$ Marks, see note 3 above.

${ }^{236}$ R Plotkin, see note 3 above, at 8; R Abbott, "I Think", see note 6 above, at 51-52.

${ }^{237}$ B Hall, see note 171 above, at 579.
} 